\title{
THE EFFECT OF DEMAND UNCERTAINTY ON A PRECOMMITIED MONOPOLY PRICE
}

\author{
Miles S. KIMBALL *
}

University of Michigan, Ann Arbor, MI 48109, USA

Received 25 October 1988

Accepted 8 January 1989

Under plausible conditions on the shape of a monopolist's or a monopolistic competitor's cost function, multiplicative demand uncertainty is shown to raise the firm's optimal precommitted price. It is argued that this effect can be substantial.

\section{Introduction}

A recent strand of thinking in Neo-Keynesian macroeconomics has emphasized the theory of monopolistic competition, in conjunction with small fixed costs of changing prices, as a basis for price rigidity. Given that picture of monopolistically competitive firms that at least temporarily precommit to a certain price, it is natural to consider the effect of demand uncertainty on the optimal precommitted price. ${ }^{1}$

\section{The direction of the effect}

For simplicity, let us take the number of firms to be fixed. ${ }^{2}$ In a one-period model, a monopolist or monopolistic competitor will then face the optimization problem:

$$
\max _{p} \mathrm{E} \Pi(p, x)
$$

where $I$ is total profits, $p$ is the firm's precommitted price and $x$ is a demand shifter. The first-order condition is

$$
\mathrm{E} \Pi_{p}(p, x)=0
$$

where the subscript shows a partial derivative in the obvious manner. Variance in the level of demand as indexed by $x$ will disturb this first-order condition and thereby affect the optimal

* I would like to thank David Romer and Larry Ball for stimulating my interest in this topic, and Robert Barsky for helpful discussions.

1 This paper owes its existence to Ball and Romer (1987), who introduce this issue, but do not fully resolve it, since they are concentrating on a different set of issues.

2 An earlier version of this paper included a discussion of entry and exit which could not be included because of space constraints. 
precommitted price; in particular, using a second order Taylor expansion of $\Pi_{p}$, one finds that for a small amount of uncertainty in $x$,

$$
\frac{\partial p^{*}}{\partial\left(\sigma_{x}^{2}\right)} \approx \frac{1}{2} \frac{\Pi_{p x x}}{\left(-\Pi_{p p}\right)}
$$

A mild strengthening of the second-order condition insures that the denominator of (3) is positive, so it can readily be seen that the sign of the effect of a small amount of demand uncertainty depends on the sign of $\Pi_{p x x}$.

More generally, assuming that $\mathrm{E} \Pi_{p p}<0$ for any relevant probability distribution of $x$, we can use the results of Rothschild and Stiglitz (1970) to show that if $\Pi_{p x x}$ is positive for all values of $x$, any mean-preserving spread of the probability distribution of $x$ will unambiguously raise $\mathrm{E} \Pi_{p}$ and will therefore raise the optimal precommitted price, while if $\Pi_{p x x}$ is ncgative for all values of $x$, any mean preserving spread of $x$ will unambiguously lower $E \Pi_{p}$ and therefore the optimal price.

Without putting any restrictions on the type of demand shifts we are considering, little more can be said about whether demand uncertainty raises or lowers the optimal precomitted price. However, a very natural specification of demand shifts - as proportional increases in the quantity demanded at every price - coupled with reasonable conditions on the shape of the cost function, will make the effect of demand uncertainty on the optimal price unambiguously positive.

To be specific, let the quantity demanded at any price be $x f(p)$ and the cost of producing this quantity of output be $c[x f(p)]$. Then,

$$
\begin{aligned}
& \Pi(p, x)=p x f(p)-c(x f(p)), \\
& \Pi_{p}(p, x)=x\left[f(p)+p f^{\prime}(p)-f^{\prime}(p) c^{\prime}(x f(p))\right], \quad \text { and } \\
& \Pi_{p x x}=-f^{\prime}(p) f(p)\left[2 c^{\prime \prime}(x f(p))+x f(p) c^{\prime \prime \prime}(x f(p))\right] .
\end{aligned}
$$

Since $-f^{\prime}(p) f(p)$ will always be positive as long as the demand curve slopes down, the sign of $\Pi_{p x x}$ is just the sign of $2 c^{\prime \prime}(y)+y c^{\prime \prime \prime}(y)$, where $y=x f(p)$ is the ex post amount of output produced. ${ }^{3}$ The first term, $2 c^{\prime \prime}(y)$, is positive as long as marginal costs are increasing in the quantity of output. The second term, $y c$ "' $(y)$, will be non-negative as long as the marginal cost function $c^{\prime}(y)$ is convex. We can argue for convex marginal costs, first, based on the intuition that informs most textbook illustrations of the marginal cost function, and second, based on the intuitive notion of 'capacity output', which seldom refers to an absolute maximum amount of production, but rather to a point after which marginal costs rise very rapidly. If marginal costs tend to be relatively constant or rise slowly at low levels of output and rise more rapidly at higher levels of output marginal costs will be convex. The two assumptions of increasing and convex marginal costs together make the effect of multiplicative demand uncertainty on the optimal precommitted monopoly price unambiguously positive. ${ }^{4}$

3 Thus, the specification of demand shifts as (horizontally) multiplicative prevents any influence of the shape of the demand function on the sign of $\Pi_{p x x}$, making it depend only on the shape of the cost function.

4 As is clear from the equations above, convex and increasing marginal costs are sufficient but not necessary for this result. As long as the marginal cost function is never concave enough for a negative value of $y c^{\prime \prime \prime}(y)$ to overwhelm the effect of increasing marginal costs $2 c^{\prime \prime}(y)$, and as long as marginal costs are never decreasing fast enough for a negative value of $2 c^{\prime \prime}(y)$ to overwhelm the effect of convex marginal costs $y c^{\prime \prime \prime}(y)$, the result will still hold. 
The economic interpretation of this result is straightforward. Convex marginal costs imply that the expected marginal cost of producing one more unit in every state of demand will be increased by a mean-preserving spread. Increasing marginal costs mean that high marginal costs occur in states of high demand when a change in price has a bigger absolute effect on the quantity sold, so that lower prices tend to increase the amount sold by a greater absolute amount in those states in which producing and selling more is worst for the firm. Put together, these two assumptions about marginal cost clearly imply that a price reduction is less attractive in the face of uncertain demand and a price increase is more attractive.

One important aspect of the story is the assumption that the firm must precommit to a given price in the sense of guaranteeing to provide the product to all takers at that price. If the firm has a set price but can ration consumers in periods of high demand, then as far as production costs are concerned, the upper end of distribution of $x$ is effectively collapsed onto the value of $x$ that indicates the maximum amount the firm is willing to sell at its precommitted price. This might require some modification of the statements above to apply to this modified distribution of $x$. However, if rationing consumers has indirect costs (perhaps from upsetting those consumers and thereby losing future business) that are only a little below the costs of making the product available to them, the possibility of rationing may not change things much.

\section{The size of the effect}

One approach to gauging the size of the effect of demand uncertainty on the optimal precommitted monopoly price would he to calculate the value of $-\Pi_{p x x} / \Pi_{p p}$ at various points. This is not hard to do, and should afford some enlightenment to the interested reader. But this measure of the effect of demand uncertainty on a monopoly price has the two disadvantages of depending intimately upon the exact shape of the demand curve, and applying in a strict sense only to small demand risks. Here we will develop another measure which (1) depends almost entirely on the shape of the cost function alone with very little dependence on the exact shape of the demand function, and (2) applies equally well to small and large risks. This is the Arrow-Pratt analog measure of the firm's 'skittishness', $\Pi_{p x x} / \Pi_{p x}$, which compares the effect of uncertainty in the demand shifter $x$ to the effect of a straightforward increase in $x$.

To motivate $\Pi_{p x x} / \Pi_{p x}$ as a measure of the firm's 'skittishness' in the face of demand uncertainty, note that for small changes in $x$, the effect on the optimal price is given by

$\partial p^{*} / \partial x=\Pi_{p x} /\left(-\Pi_{p p}\right)$,

so that if we give the name $\xi$ to the 'certainty equivalent' to a small risk in $x$ in the sense of having the same effect on the optimal price, then this certainty equivalent increase in $x$ is given approximately by

$\frac{\Pi_{p x}\left(p, x_{0}\right)}{\left(-\Pi_{p p}\left(p, x_{0}\right)\right)} \xi \approx \frac{\Pi_{p x x}\left(p, x_{0}\right)}{\left(-\Pi_{p p}\left(p, x_{0}\right)\right)} \frac{\sigma_{x}^{2}}{2}$

or

$\xi=\frac{\Pi_{p x x}\left(p, x_{0}\right)}{\Pi_{p x}\left(p, x_{0}\right)} \frac{\sigma_{x}^{2}}{2}=$ 


$$
\begin{aligned}
& =\frac{-f^{\prime}(p) f(p)\left[2 c^{\prime \prime}\left(x_{0} f(p)\right)+x_{0} f(p) c^{\prime \prime \prime}\left(x_{0} f(p)\right)\right]}{f(p)+p f^{\prime}(p)-f^{\prime}(p) c^{\prime}\left(x_{0} f(p)\right) x_{0} f^{\prime \prime}(p) f(p) c^{\prime \prime}\left(x_{0} f(p)\right)} \frac{\sigma_{x}^{2}}{2} \\
& =\frac{-f^{\prime}(p) f(p)\left[2 c^{\prime \prime}\left(x_{0} f(p)\right)+x_{0} f(p) c^{\prime \prime \prime}\left(x_{0} f(p)\right)\right]}{-x_{0} f^{\prime}(p) f(p) x^{\prime \prime}\left(x_{0} f(p)\right)} \frac{\sigma_{x}^{2}}{2} \\
& =\left[2+\frac{c^{\prime \prime \prime}\left(x_{0} f(p)\right) x_{0} f(p)}{c^{\prime \prime}\left(x_{0} f(p)\right)}\right] \frac{\sigma_{x}^{2}}{2 x_{0}},
\end{aligned}
$$

where $f(p)+p f^{\prime}(p)-f^{\prime}(p) c^{\prime}\left(x_{0} f(p)\right)$ is equal to zero ${ }^{5}$ because it is $\Pi_{p}\left(p, x_{0}\right) / x_{0}$. Using this approximation, one can see that if marginal cost is convex at all, then the effect of demand uncertainty on price is greater than the effect of a certain increase in demand equal to $\sigma_{x}^{2} / x$. Since one can normalize $x$ to be equal to 1 at the mean level of demand, this result is readily interpretable. It says for example (assuming the small-risk approximation is reasonably accurate) that demand uncertainty with a standard deviation equal to $10 \%$ of average demand should cause a price increase at least as great as a certain increase in demand of $1 \%$. Thus, the effect we are investigating is likely to be substantial in many actual situations where there is a large amount of demand uncertainty over the period of time a price is held fixed.

For large risks, we can define the certainty-equivalent increase in $x$ by the equation

$\mathrm{E} \Pi_{p}\left(p, x_{0}+\tilde{x}\right)=\Pi_{p}\left(p, x_{0}+\xi\right)$,

where $x_{0}$ is the mean of the original distribution of $x$ and $\tilde{x}$ is the mean-zero random variable $x-x_{0}$. Then, as is done in Kimball (1988) for precautionary saving premia, we can apply Pratt's (1964) mathematical results about risk premia to show for two monopolists with possibly different optimal prices, that if for every value of $x, \Pi_{p x x} / \Pi_{p x}$ is greater for the first monopolist than the second, ${ }^{6}$ then the certainty equivalent increases in $x$ is greater for the first monopolist than for the second. ${ }^{7}$ In other words, if this measure of the responsiveness of price to demand uncertainty is uniformly higher for the first monopolist, then a given uncertainty in $x$ has the same effect on price as a large increase in demand for the first monopolist than for the second. By making a comparison between the monopolist one is interested in and another monopolist with a convenient form of cost function, it is not difficult to put a lower bound on the effect of demand uncertainty on price in any given case.

\section{Conclusion}

For macroeconomics, one of the most interesting aspects of the above results is that if menu costs cause prices to be set in nominal terms, the 'demand uncertainty' mentioned in these results can be caused not only by real factors, but also by purely nominal disturbances to the money supply or by

5 Therefore the denominator will be positive as long as marginal cost is increasing.

6 Note that while $\mathrm{E} \Pi_{p}=0, \Pi_{p}$ need not be zero for every realization of $x$, so the denominator $\left(\Pi_{p x}\right)$ will not simplify as it does for the case of small risks. This means that the assumption that $\Pi_{p x}(p, x)$ is positive for all possible realizations of $x$, which is needed in order to apply Pratt's theorems, is more restrictive than the simple assumption of increasing marginal costs.

7 See especially Appendix $C$ in Kimball (1988). In the case here, sine $\Pi_{p x x} / \Pi_{p x}$ will be positive, one must make use of the fact that Pratt's results reply to risk-loving as well as to risk-averse agents, and make appropriate sign adjustments. 
disturbances in the demand for (and therefore the velocity of) money. Since macroeconomic models of monopolistic competition typically deliver the result that the initial equilibrium already has too little output because of an aggregate demand externality, ${ }^{8}$ any increase in price (and consequent reduction in average output) due to demand uncertainty is likely to be harmful. Conversely, by reducing the demand uncertainty faced by firms that have precommitted nominal prices, macroeconomic stabilization can lead to lower prices, higher mean output, and a consequent improvement in welfare. ${ }^{9}$ The future, no doubt, will bring more complete models of this adverse effect of aggregate demand variability on overall welfare.

\section{References}

Ball, Laurence and David Romer, 1987, Real rigidities and the non-neutrality of money, NBER working paper no. 2432, Oct. Blanchard, Olivier Jean and Nobuhiro Kiyotaki, 1987, Monopolistic competition and the effects of aggregate demand, American Economic Review 77, Sept., 647-666.

Kimball, Miles S., 1988, Precautionary saving in the small and in the large, Mimeo., Jan.

Pratt, John W., 1964, Risk aversion in the small and in the large, Econometrica 32, 122-136.

Rothschild, Michael and Joseph E. Stiglitz, 1970, Increasing risk I: A definition, Journal of Economic Theory 2, $225-243$.

8 See for example Blanchard and Kiyotaki (1987).

9 Another possible benefit of stabilization can be seen in the analysis of Section 4 . Lower demand uncertainty reduces the variability of the quantity produced and may thereby reduce expected costs of production. 